\title{
ESTUDO DAS VIBRAÇÕES GERADAS POR DETONAÇÕES FEITAS NA OBRA CIVIL DA ECLUSA 2 DE TUCURUÍ (PA)
}

\author{
George Sand França ${ }^{1}$, Marcos Alberto Rodrigues Vasconcelos², \\ Cristiano Naibert Chimpliganond ${ }^{1}$ e Sidinei Sebastião Tomás ${ }^{1}$
}

Recebido em 8 janeiro, 2010 / Aceito em 4 fevereiro, 2011

Received on January 8, 2010 / Accepted on February 4, 2011

\begin{abstract}
The construction of the Tucurui dam in the decade of 80 , situated in the River Tocantins, interrupted the navigation in this stretch of the watercourse. To give continuity to the passage of the fluvial transports the Eletronorte and Camargo Corrêa S.A., initiated the construction of two canals in the neighborhoods of the city of Tucuruí/PA. Floodgate 1 is connected to the axis of the dam, and Floodgate 2 will be situated near the city of Tucuruí, in the left edge of the Tocantins River. The dismounting of the rocks caused discomfort to the population which complained about damages in the residences. In this way, the Seismological Observatory of the University of Brasilia monitored the vibrations generated by blasting, with the aim to make a diagnosis and see if there is a relation between the detonations and the residences cracks. The velocity records of the particle vibration were obtained by engineering seismometer installed near the damaged residences. Records of 27 distinct points were analysed, and these information were intercorrelated with geological, pedological and geotechnical data, to understand its effects and to obtain the equation of seismic attenuation for this region. The 42 values of the particles velocity obtained were below the recommended value of $15 \mathrm{~mm} / \mathrm{s}$ defined by the Brazilian norms as the upper level to avoid damages to the nearby residences. Regarding the sound pressure only one single measured value was beyond the intensity established by the Brazilian norms.
\end{abstract}

Keywords: removal of rock, seismograph monitoring, vibration, equation of attenuation.

RESUMO. A construção da barragem de Tucuruí na década de 80, situada no Rio Tocantins, interrompeu a navegação neste trecho da hidrovia. Para dar continuidade ao trajeto dos transportes fluviais a Eletronorte, por meio da Camargo Corrêa S.A., iniciou a construção de duas eclusas nas proximidades da cidade de Tucuruí/PA. A Eclusa 1 localiza-se conectada ao eixo da barragem, e a Eclusa 2 localizar-se-á nas proximidades da cidade de Tucuruí, na margem esquerda do Rio Tocantins. Esta proximidade fez com que o desmonte das rochas relacionado à sua construção provocasse desconforto à população e reclamações quanto a danos às residências. Desta maneira, o Observatório Sismológico da Universidade de Brasília realizou o monitoramento das vibrações geradas pelas detonações, com o fito de se diagnosticar se há relação entre as detonações executadas e as fissuras residenciais. Os registros das velocidades de vibração de partícula foram obtidos utilizando sismômetros de engenharia instalados nas proximidades das residências teoricamente prejudicadas. Foram analisados registros de 27 pontos distintos e essas informações foram interseccionadas a informações geológicas, pedológicas e geotécnicas, de forma a se entender seus efeitos e se obter a equação de atenuação das ondas para esta região. Os 42 valores de velocidade da partícula obtidos mostraram-se inferiores ao valor recomendado pela norma ABNT de $15 \mathrm{~mm} / \mathrm{s}$ para que não ocorram danos às residências proximais. No que diz respeito à intensidade sonora, somente um valor apresentou-se superior ao limite estabelecido pela norma.

Palavras-chave: desmonte de rocha, monitoramento sismográfico, vibrações, equação de atenuação.

\footnotetext{
${ }^{1}$ SG 13, Campus Universitário Darcy Ribeiro, Asa Norte, Observatório Sismológico, Instituto de Geociências, Universidade de Brasília, DF, Brasil. Tel.: +55 (61) 3107-1298; Fax: +55 (61) 3274-5927 -E-mails: georgesand@unb.br; naibert@unb.br; sidinei@unb.br

${ }^{2}$ SG 13, Campus Universitário Darcy Ribeiro, Asa Norte, Observatório Sismológico, Instituto de Geociências, Universidade de Brasília, DF, Brasil. Endereço atual: Instituto de Geociências, Universidade de Campinas. Tel.: +55 (19) 3521-5151 - E-mail: vasconcelos@ige.unicamp.br
} 


\section{INTRODUÇÃo}

A Usina Hidrelétrica (UHE) Tucuruí/PA situa-se no Rio Tocantins, a 250 quilômetros de sua foz, distando aproximadamente 300 quilômetros da cidade de Belém. Sua construção foi iniciada em 1976 pela Eletronorte, sendo que sua operação comercial teve início em 1984. A construção da barragem seccionou a hidrovia, impondo a realização de uma obra de navegação de grande porte capaz de vencer 0 desnível de 72 metros criado. Dessa forma, 0 aproveitamento de Tucuruí compreende, também, um sistema de transposição localizado na margem esquerda do Rio Tocantins e constituído por duas eclusas e um canal intermediário. 0 objetivo precípuo é dar continuidade à navegação no trecho da hidrovia interrompido com a construção da barragem.

A Eclusa 1 se conecta pela Cabeça de Montante ao eixo da Barragem de Terra da Margem Esquerda, através de quatro blocos de muros de ligação. A Eclusa 2 está localizada junto à margem esquerda do Rio Tocantins, próximo à cidade de Tucuruí/PA. Está posicionada de tal forma que dois terços de sua estrutura estão encaixados em rocha e tem a finalidade de redirecionar o fluxo do Rio Tocantins.

Com 0 início das obras relativas à Eclusa 2 (Fig. 1), iniciouse 0 desmonte de rochas com emprego de explosivos gerando vibrações no solo em áreas urbanas. Em muitos países existem normas limitando os níveis de vibração como forma de proteção às propriedades vizinhas de acordo com o tipo de construção edificada. No Brasil, a norma que mais diz respeito aos limites de vibração e de pressão acústica aceitáveis é a Norma Brasileira (NBR) 9653 (ABNT, 2005).

Para que os níveis de vibração atingidos durante as detonações sejam controlados e/ou atenuados, é necessário o monitoramento sismográfico. As informações sismológicas coletadas, processadas e apresentadas neste trabalho foram interseccionadas a informações geológicas e pedológicas. Todas essas informações, também, se fizeram importantes para 0 planejamento dos locais em que se fariam as medições, somadas às queixas dos moradores e informações pedológicas, para posterior entendimento e correlação com a equação matemática de atenuação a ser obtida.

Desta maneira, este trabalho concerne à apresentação dos dados coletados em duas etapas de campo (27.10.2007 a 30.10.2007, e 10.02.2008 a 25.02.2008), baseada na análise e interpretação dos valores obtidos, pretende-se diagnosticar se houve inerente relação das detonações executadas para a construção da Eclusa 2 da UHE Tucuruí com as fissuras existentes em algumas residências da cidade. Para isso foram moni- toradas 14 detonações, sendo 10 a céu aberto e 4 subterrâneas, em 27 pontos distintos, que contribuíram para a análise de sinais sísmicos triaxiais e da componente sonora.

\section{CONTEXTO GEOLÓGICO-PEDOLÓGICO DA REGIÃO DE MONITORAMENTO}

A região de Tucuruí situa-se entre as rochas pré-cambrianas do Complexo Xingu e as rochas metamórficas do Grupo Tocantins. As rochas do Grupo Tocantins, Iocalizadas nas margens leste e oeste do Rio Tocantins, são separadas por uma falha de empurrão ao longo da qual o rio se desenvolveu (Camargo Corrêa S.A., 2002a). Na margem esquerda, mais especificamente, distinguem-se três unidades estratigráficas como metabasalto e metassedimentos da Formação Tucuruí, além de sedimentos quaternários (Fig. 2).

0 basalto ocorre na forma de derrames que constituem camadas maciças com variação de espessura de poucos metros a mais de 40 metros. É uma rocha de baixo grau metamórfico, e apresenta metassedimentos de até 3 metros de espessura entre os derrames e brecha basáltica nos contatos com os derrames. 0 conjunto total dos derrames apresenta cerca de 150 metros de espessura superpostos por um pacote de metassedimentos com dezenas de metros de espessura. Coluviões e aluviões são os representantes dos sedimentos quaternários, e que estão nas camadas mais superficiais da área de estudo. 0 colúvio distribuise amplamente por toda área com cerca de 6 metros de espessura, enquanto os aluviões ocorrem nas proximidades do Rio Tocantins, nas regiões com relevo mais plano.

A área correspondente ao túnel da Eclusa 2 é caracterizada por um horizonte espesso de solo silto-arenoso sobreposto à camada saprolítica pouco espessa. A rocha é um metassiltito fraturado que se encontra próximo à cota de 23 metros, de forma que as fraturas são preenchidas por epidoto e/ou calcita. Cerca de 7 metros abaixo deste ponto observa-se 0 contato do metassiltito com o metabasito (Camargo Corrêa S.A., 2002b).

\section{Caracterização geológica-pedológica da região monitorada}

A partir de uma análise associativa das seções geológicogeotécnicas apresentadas nos mapas ST-TUC/04-3027, STTUC/04-3003, ST-TUC/00-0002, ST-TUC/04-2002, ST-TUC/042003, ST-TUC/04-3005, ST-TUC/04-3008, do relatório Camargo Corrêa S.A. (2002a) e nos mapas 46-MT-GE0-A1-E-003-011 e 46-MT-GE0-A1-E-003-015 do relatório Camargo Corrêa S.A. (2002b), nota-se que as mesmas tendem a apresentar, de forma 


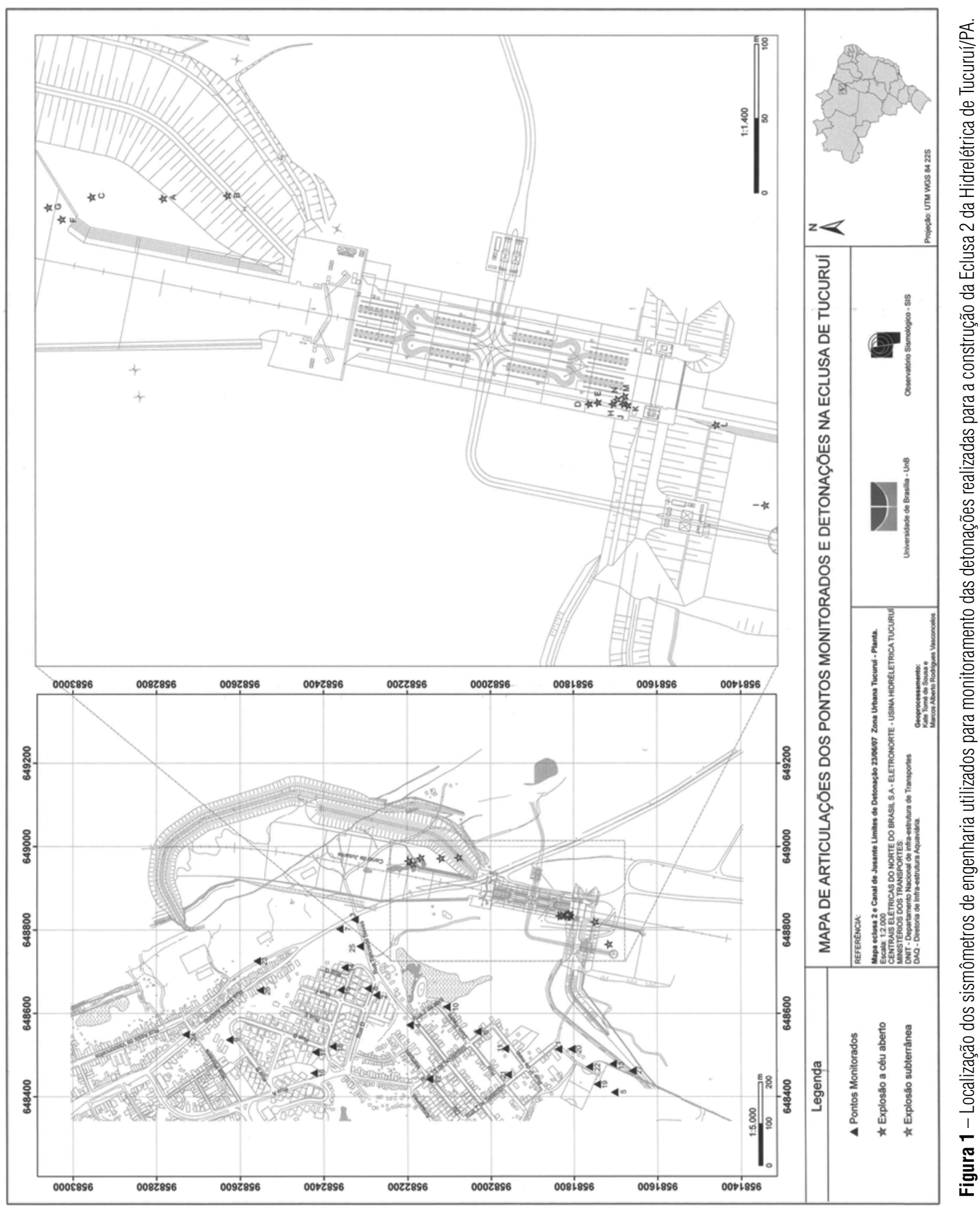




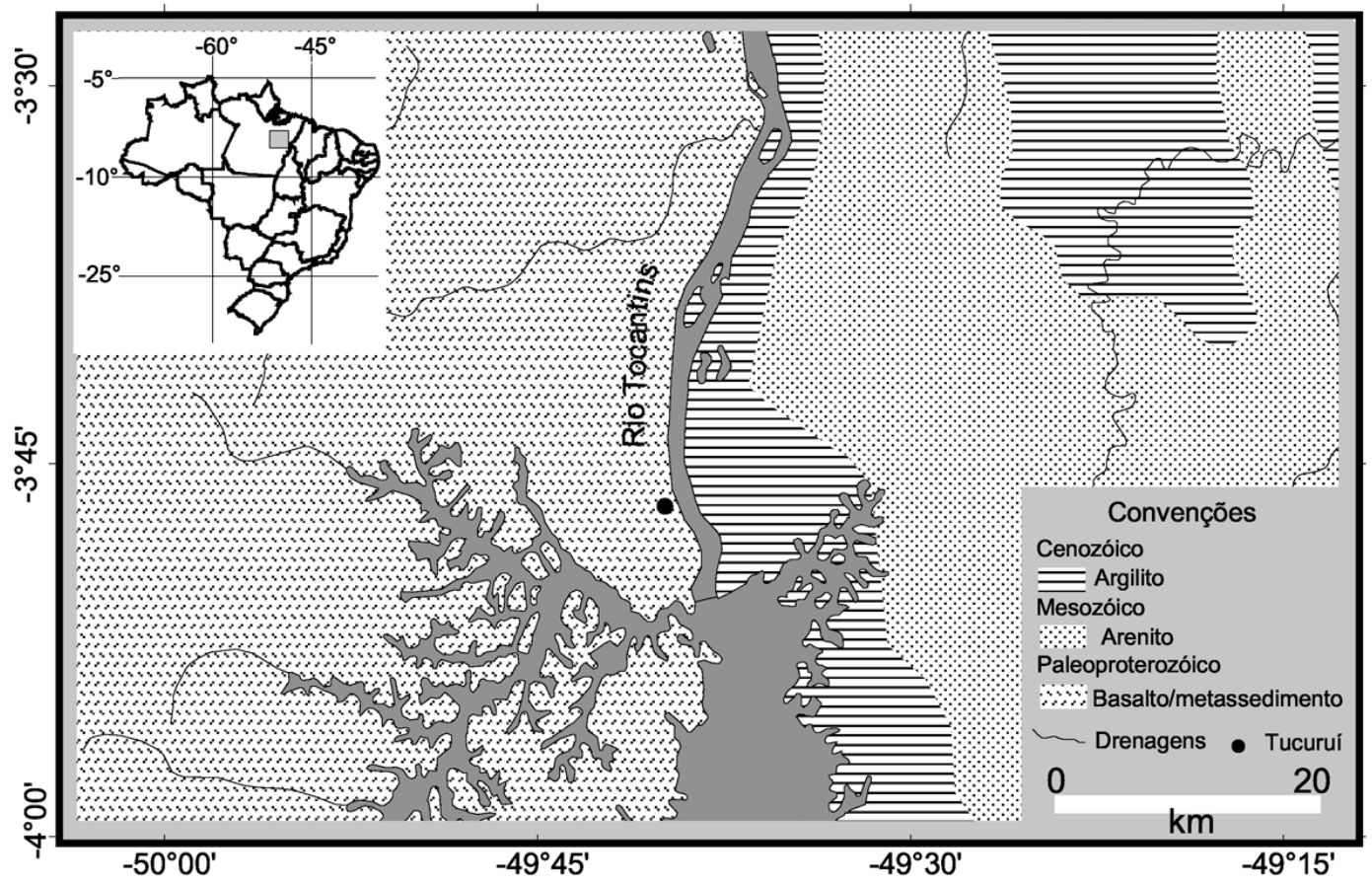

Figura 2 - Mapa geológico característico da região de estudo.

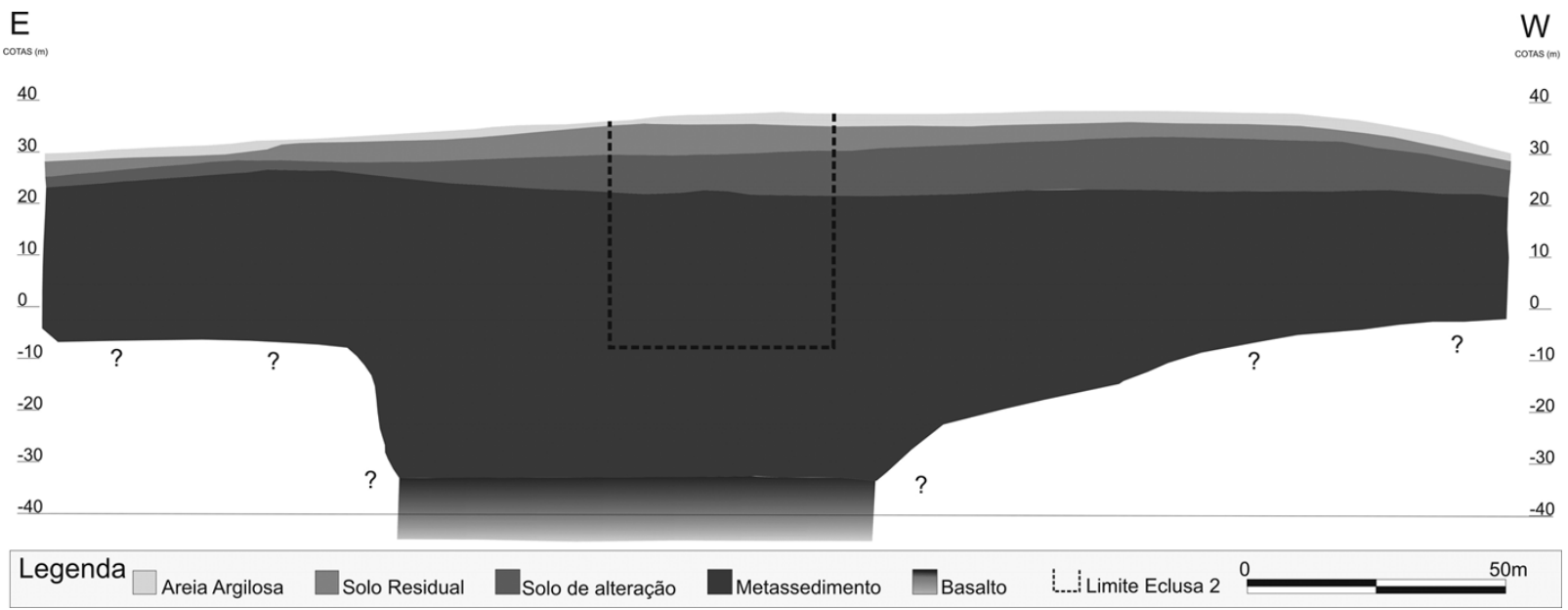

Figura 3 - Modelo de seção geológica para a região de estudo, extraído do mapa ST-TUC/04-3005 (Camargo Corrêa S.A., 2002a).

geral, camadas com espessuras relativamente homogêneas com pouca variação faciológica. Um exemplo geral desta assertiva é apresentado na Figura 3, que mostra o basalto como camada inferior sobreposto por metassedimentos, solo de alteração, solo residual, e uma camada de areia argilosa na porção mais externa.

Com o auxílio destas informações, entende-se que não haja variações bruscas sob os pontos em que foram fixados os sismômetros de engenharia. Nas regiões em que os perfis geológicos alcançam as proximidades da margem do rio, ainda é descrito um pacote aluvionar, sobreposto ao solo de alteração, com espessura de aproximadamente 5 metros, não discriminado na Figura 3.

Como consideração inicial, ressaltamos que o solo arenoargiloso (colúvio) é o que apresenta amplo domínio na região monitorada e estes estratos geológicos e pedológicos associados são os principais responsáveis pela atenuação das ondas ao longo de seu trajeto até atingirem as residências proximais. 


\section{BASE DE DADOS \\ Aquisição dos dados}

Para a coleta dos dados utilizaram-se quatro sismômetros de engenharia (1 sismômetro Blastmate III ${ }^{\mathrm{TM}}$ e 3 sismômetros Minimate Plus ${ }^{\top M}$, Instantel Inc.), instalados em regiões próximas de construções que aparentemente mostram-se prejudicadas pelas detonações ou mesmo na base da residência. Estes sismômetros são dotados de resposta de frequência de 2 a $250 \mathrm{~Hz}$ e capacidade de processamento padrão de 1.024 amostras por segundo por canal. As amplitudes limites para registro de velocidade de partícula variam entre $0,127 \mathrm{~mm} / \mathrm{s}$ e $254 \mathrm{~mm} / \mathrm{s}$, com resolução de $0,127 \mathrm{~mm} / \mathrm{s}$. 0 sismógrafo foi configurado em modo de disparo para os seguintes níveis: $100 \mathrm{~dB}$ para a onda sonora captada pelo microfone e $0,2 \mathrm{~mm} / \mathrm{s}$ para o sinal sísmico do geofone.

Um dos parâmetros, segundo a NBR 9653 (ABNT, 2005), que deve ser monitorado para a análise dos efeitos provocados por detonações é a velocidade de vibração de partícula de pico. É reconhecido como um parâmetro bastante significativo no que tange à avaliação de danos causados às estruturas (Koppe et al., 2001).

Pela análise da velocidade vibração de partícula de pico, referida como PPV (Peak Particle Velocity), a NBR 9653 (ABNT, 2005) recomenda que os danos induzidos sejam avaliados levando-se em consideração a magnitude e a frequência de vibração de partícula, os limites para velocidade de vibração de partícula de pico acima dos quais podem ocorrer danos como visto na Figura 4. Também nesse trabalho usamos 0 valor obtido pela soma resultante $(V R)$ das três componentes máximas de PPV: Velocidade máxima de partícula no eixo longitudinal $(V L)$, vertical $(V V)$ e transversal $(V T)$, independentemente do tempo decorrido após a detonação em cada um desses eventos. Esse valor é calculado conforme a Equação (1):

$$
V_{R}=\sqrt{V L^{2}+V V^{2}+V T^{2}}
$$

A velocidade resultante $V R$ corresponde ao maior valor resultante obtido entre as resultantes de cada momento.

Para a coleta de todos os dados foram realizados dois trabaIhos de campo: um primeiro, no mês de outubro de 2007, e um segundo, no mês de fevereiro de 2008, que totalizam 27 pontos (Tab. 1). Os dados obtidos foram agrupados com as distâncias entre as frentes detonadas e os pontos de monitoramento.

Para cada ponto de coleta de dados, os sismômetros de engenharia foram instalados, tomando como precaução a orientação dos sensores e microfones na direção do foco da explosão. Estes sensores foram locados na base das construções monitoradas, conforme recomendação da ABNT, ou na região de solo mais próxima. Quando instalado em solo a fixação é realizada com pinos, observadas as recomendações existentes (Instantel Inc., 1998a, b). Quando locado na base da estrutura, utilizou-se gesso para sua fixação.

A área designada para os estudos de vibração situa-se na margem oeste do Rio Tocantins, mais precisamente na zona residencial da cidade de Tucuruí, na qual os moradores mostramse preocupados com a segurança de suas moradias. Os pontos de monitoramento foram escolhidos com de acordo com as informações dos moradores, local de ocorrência das detonações e informações geológicas e pedológicas (Fig. 1).

\section{Análise e interpretação dos dados}

Os riscos de ocorrência de danos induzidos por vibrações do terreno devem ser avaliados levando-se em consideração a magnitude e a frequência da velocidade de vibração de partícula de pico. Como cada tipo de estrutura apresenta uma frequência natural de vibração, pode-se estabelecer um limite de velocidade de vibração de partícula de pico $(\mathrm{mm} / \mathrm{s})$ aceitável em áreas residenciais para que não ocorram danos às mesmas. A Associação Brasileira de Normas Técnicas (ABNT), por meio da NBR 9653 (ABNT, 1986), e posteriormente em sua revisão na NBR 9653 (ABNT, 2005), estabelece os limites de velocidade de vibração de partícula de pico para cada intervalo de frequência em áreas residenciais iniciando em $15 \mathrm{~mm} / \mathrm{s}$ na frequência de $4 \mathrm{~Hz}$ e crescendo até $50 \mathrm{~mm} / \mathrm{s}$ nas frequencias superiores a $40 \mathrm{~Hz}$ (Fig. 4). Isso porque a faixa de frequência natural de vibração de muitas construções varia entre 5 e $15 \mathrm{~Hz}$ (e.g. Koppe et al., 2001), o que, também, se enquadra no intervalo de frequência apresentado em normas internacionais para habitações e construções.

Após o registro das detonações, os respectivos dados foram coletados do equipamento e acessados com 0 programa Blastware 8.12 (Instantel Inc., 2006, 2007). A oscilação do chão medida pelo sismômetro é transformada em velocidade de vibração de partícula $(\mathrm{mm} / \mathrm{s})$, variável frequentemente utilizada no estudo de casos de vibração próxima a áreas urbanas.

Além do valor da velocidade de vibração de partícula, obtémse com as medidas o registro dos eventos nas três componentes do sensor, e uma componente que faz a medição da pressão acústica (Fig. 5b).

É possível também obter os gráficos dos espectros das frequências para cada componente (Fig. 5c). Desta maneira, tornase facilmente legível o conhecimento da frequência que atinge os maiores valores de amplitude. Este tipo de análise torna-se importante no que pese 0 conhecimento da frequência de vibração da estrutura estudada, como foi mencionado acima no trabalho de Koppe et al. (2001). 


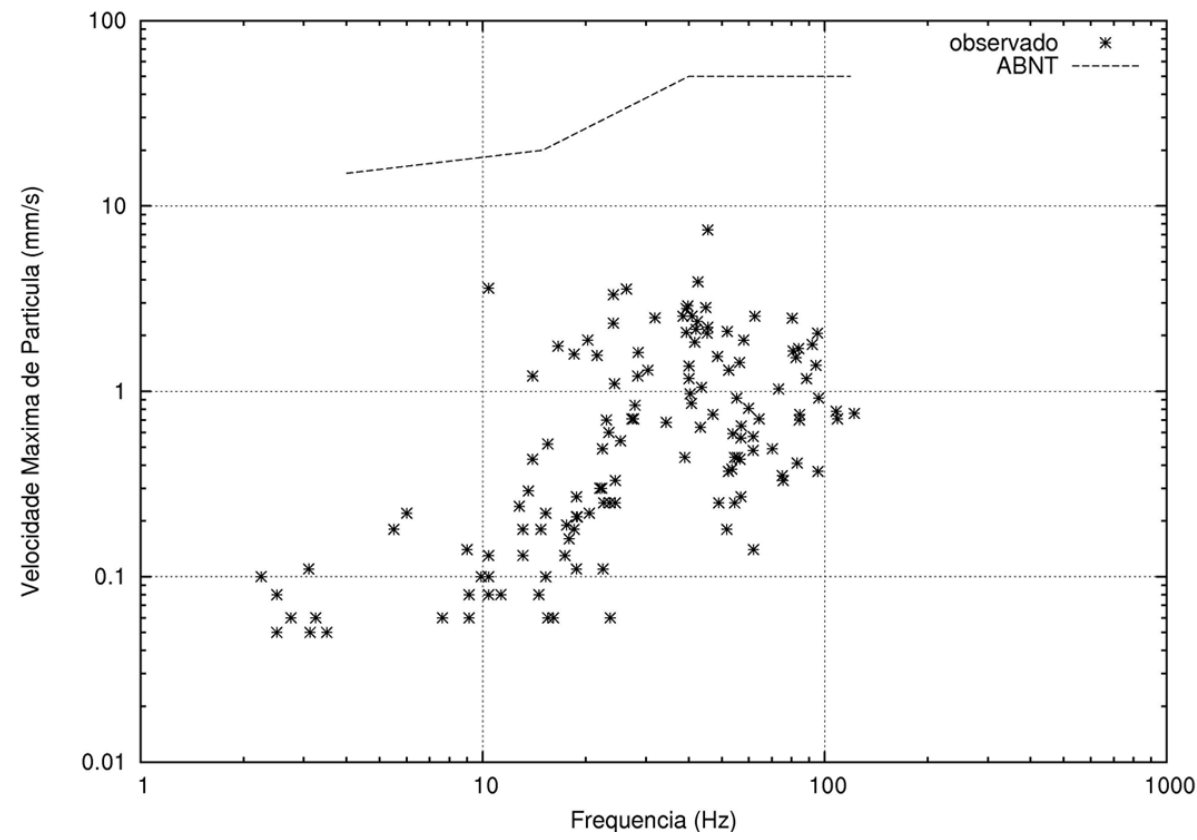

Figura 4 - Representação gráfica dos limites de velocidade de vibração de partícula por faixas de frequências aceitáveis para detonações que ocorrem próximas a áreas urbanas (ABNT, 2005).

Tabela 1 - Descrição e coordenadas geográficas dos 27 pontos monitorados.

\begin{tabular}{|c|c|c|c|}
\hline Ponto & Endereço & Lat. & Long. \\
\hline 1 & Rua 7 de setembro esquina com Travessa $1^{\circ}$ de maio & $-3,78195$ & $-49,66249$ \\
\hline 2 & Escola Municipal Plácido de Castro & $-3,77817$ & $-49,66146$ \\
\hline 3 & Rua Santo Antônio esquina com Rua Tancredo Neves & $-3,77759$ & $-49,65898$ \\
\hline 4 & Rua Tancredo Neves, № 61 & $-3,77898$ & $-49,66197$ \\
\hline 5 & Travessa São Pedro, Qd. 2, Lt. 15, Bairro Liberdade & $-3,78334$ & $-49,66356$ \\
\hline 6 & Rua 15 de novembro, № 118 & $-3,78056$ & $-49,66219$ \\
\hline 7 & Rua Santo Antônio, № 1585, Bairro Matinha & $-3,77739$ & $-49,65974$ \\
\hline 8 & Rua D, N 30, Bairro Pioneira & $-3,77799$ & $-49,66132$ \\
\hline 9 & Escola Municipal Maestro João Leite & $-3,77499$ & $-49,66243$ \\
\hline 10 & Rua Dom Pedro I, № 197, Bairro Liberdade & $-3,77952$ & $-49,66151$ \\
\hline 11 & Rua $1^{\circ}$ de maio, $N^{\circ} 177$ & $-3,78070$ & $-49,66210$ \\
\hline 12 & Rua 15 de novembro, № 91, esquina com Rua Ofir Marques & $-3,77905$ & $-49,66210$ \\
\hline 13 & Rua São Clemente, № 3 & $-3,78331$ & $-49,66294$ \\
\hline 14 & Rua G, No 2 & $-3,77749$ & $-49,66087$ \\
\hline 15 & Rua $F, N^{\circ} 2$ & $-3,77740$ & $-49,66135$ \\
\hline 16 & Rua $A, N^{\circ} 7$ & $-3,77682$ & $-49,66315$ \\
\hline 17 & Rua $B, N^{\circ} 30$ & $-3,77693$ & $-49,66248$ \\
\hline 18 & Escola Municipal Ursinho Feliz & $-3,77710$ & $-49,66243$ \\
\hline 19 & Travessa São Benedito, Qd. 1, Lt. 10 & $-3,78292$ & $-49,66311$ \\
\hline 20 & Travessa $1^{\circ}$ de maio, $\mathrm{N}^{\circ} 26$ & $-3,78292$ & $-49,66311$ \\
\hline 21 & Rua 7 de setembro esquina com Rua Dom Pedro I, № 136 & $-3,78102$ & $-49,66292$ \\
\hline 22 & Travessa $1^{\circ}$ de maio, $\mathrm{N}^{\circ} 14$ & $-3,78293$ & $-49,66309$ \\
\hline 23 & Rua Assis Vasconcelos, № $669 \mathrm{~A}$ & $-3,77559$ & $-49,66073$ \\
\hline 24 & Avenida Pioneira esquina com Rua Santo Antônio & $-3,77405$ & $-49,66280$ \\
\hline 25 & Rua Tancredo Neves, № 60 & $-3,77782$ & $-49,66041$ \\
\hline 26 & Rua Santo Antônio, No 1239, Bairro Matinha & $-3,77551$ & $-49,66119$ \\
\hline 27 & Rua São Clemente, Qd. 2, Lt. 6 & $-3,78373$ & $-49,66309$ \\
\hline
\end{tabular}


USBM RI8507 And OSMRE
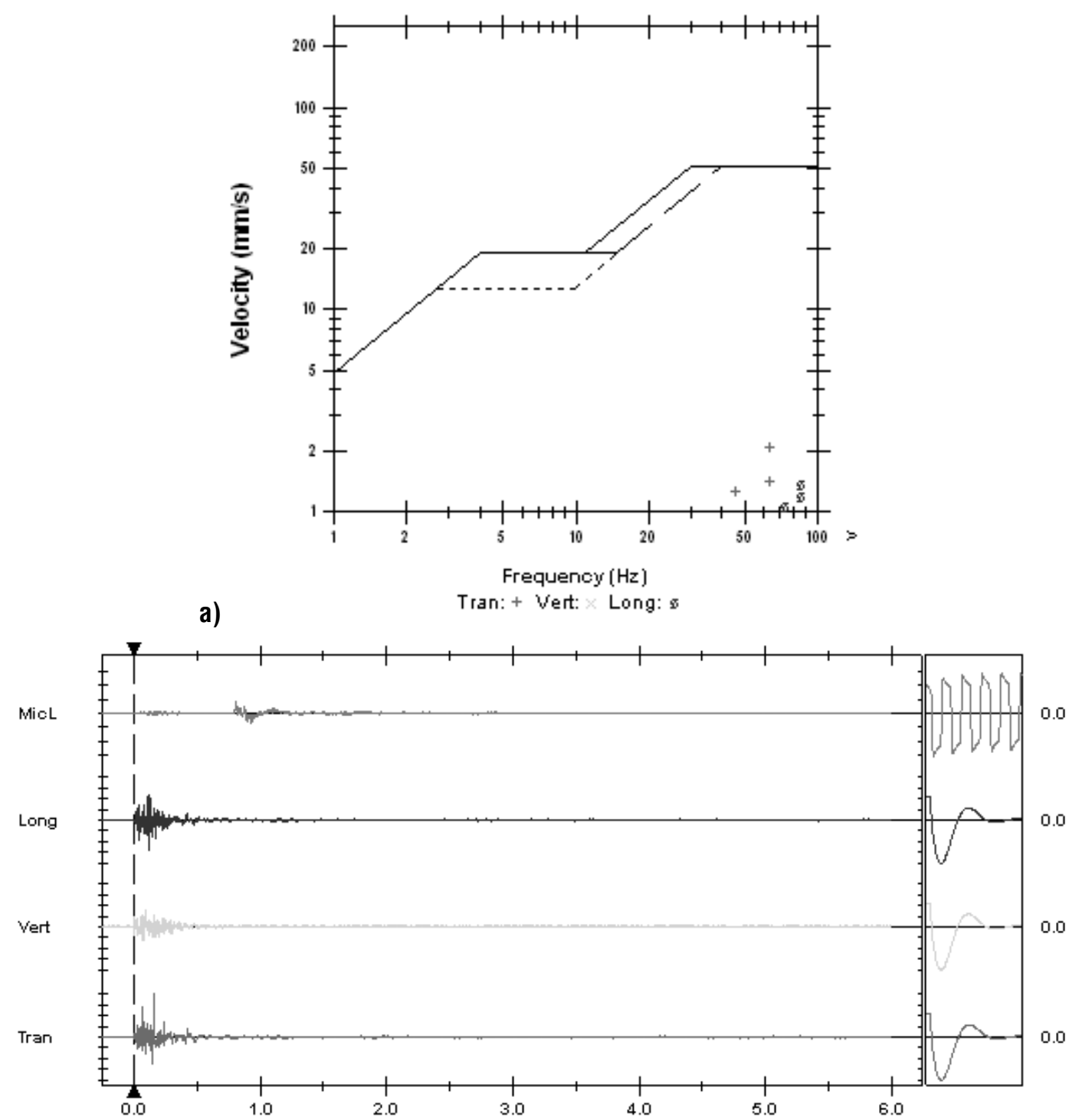

b)

Time Scale: 0.50 secidiv Amplitude Scale: Geo: $0.500 \mathrm{~mm} / \mathbf{s}^{\prime} \mathrm{div}$ Mic: $10.00 \mathrm{pa} .(\mathrm{L}) \mathrm{div}$ Trigger $=$

Sensorcheck

Figura 5 (continua) - Interfaces gráficas geradas pelo programa Blastware 8.12 (Instantel Inc., 2006, 2007). Em (a) gráfico da frequência versus velocidade da partícula; (b) registro da velocidade de partícula para cada uma das componentes transversal, vertical e longitudinal e sinal sonoro, de baixo para cima.

Reil (1998) indica que os três principais fatores relacionados à vibração no solo que determinam o quanto as estruturas construídas vibrarão e, por consequência, poderão sofrer danos e a incidência de reclamações dos moradores vizinhos são:

I. velocidade de vibração máxima de partícula de pico e vibração máxima $(V R)$,

II. duração da vibração no solo, e
III. frequência de vibração.

Os dois trabalhos de campo envolveram o monitoramento de 10 detonações a céu aberto e 4 subterrâneas, e seus locais de ocorrência estão concentrados no Canal de Jusante, Túnel de Enchimento e Tomada D'água, conforme as informações que constam nos planos de fogo. A Tabela 2 apresenta os dados referentes aos registros obtidos e demais informações necessárias para 

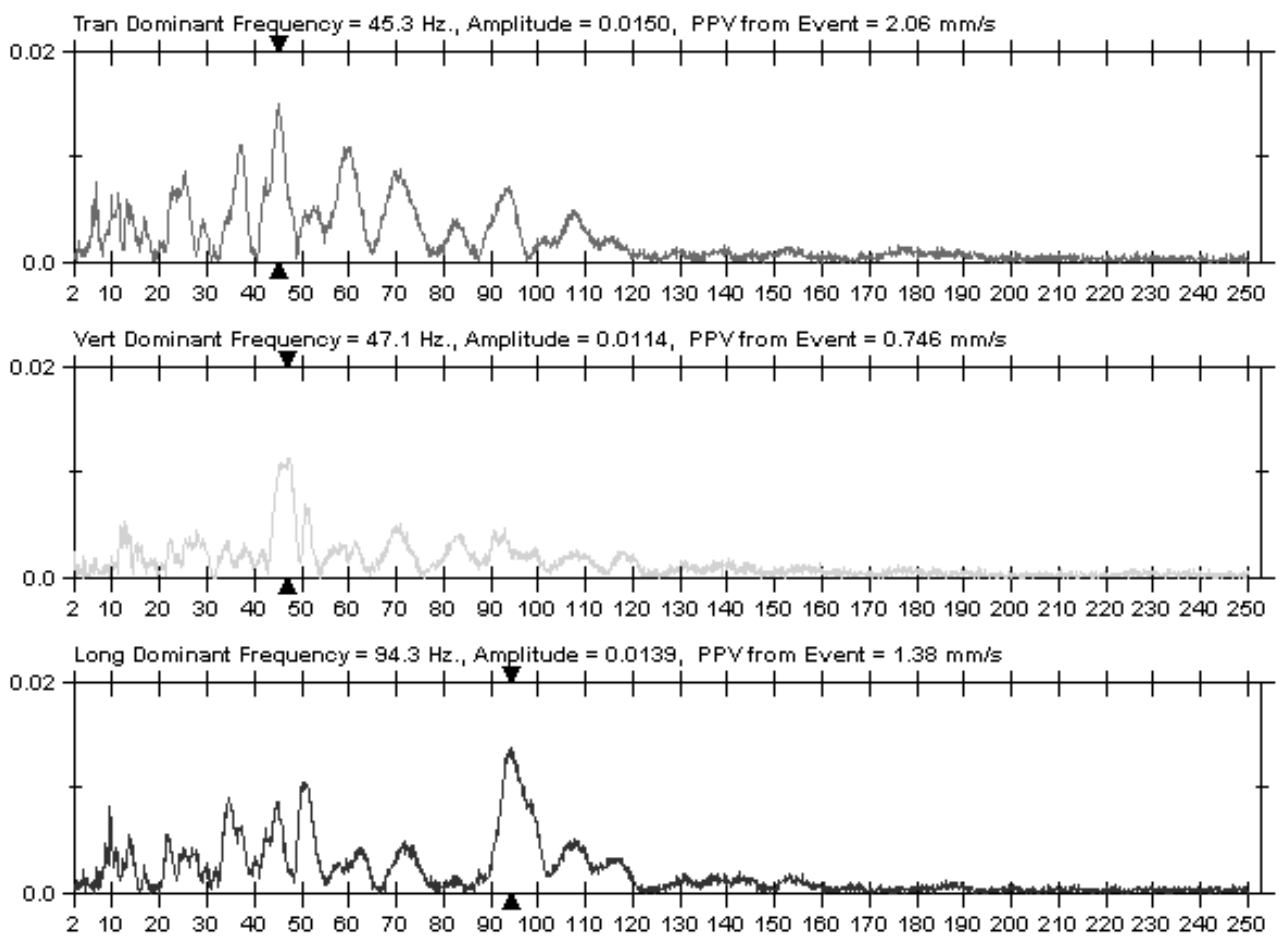

MicL Dominant Frequency $=2.88 \mathrm{~Hz}$., Amplitude $=0.202$, PSPL From Event $=8.25 \mathrm{pa}$. (L)

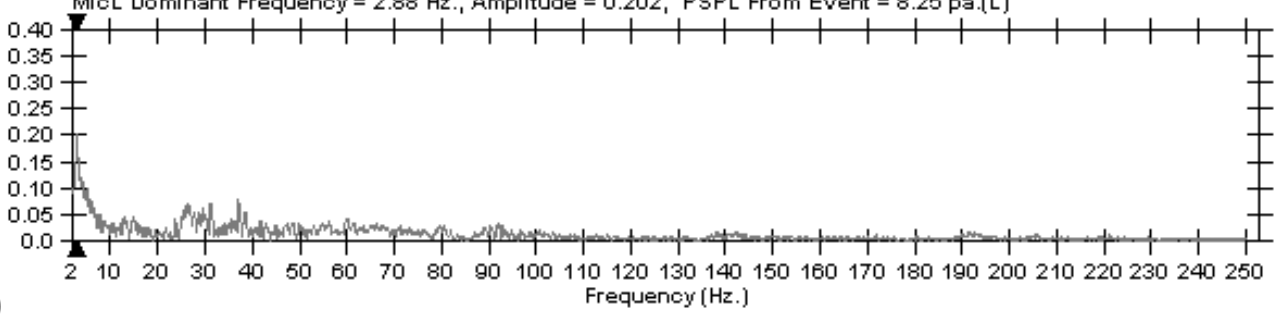

C) Frequency $(\mathrm{Hz}$.

Figura 5 (conclusão) - Interfaces gráficas geradas pelo programa Blastware 8.12 (Instantel Inc., 2006, 2007). Em (c) espectro da frequência para cada uma das componentes transversal, vertical e longitudinal e sinal sonoro, de cima para baixo.

este trabalho. Os dados concernentes à carga máxima por espera $(Q)$, dada em quilogramas, e as coordenadas das detonações necessárias para cálculo das distâncias entre o ponto de monitoramento e a detonação (Tab. 2).

Nota-se que os valores das velocidades da vibração de partículas de pico máximas da partícula mostram-se que todos os inferiores ao valor de $15 \mathrm{~mm} / \mathrm{s}$ na frequência de $4 \mathrm{~Hz}$, valor limite mínimo, segundo a norma brasileira, para que possa ocorrer danos induzidos por vibrações do terreno em estruturas urbanas. 0 histograma apresentado na Figura 6 mostra que de fato, a maior parte dos dados está concentrada na região de valores de velocidade da partícula menores que $1 \mathrm{~mm} / \mathrm{s}$, atingindo valor máximo de aproximadamente $7 \mathrm{~mm} / \mathrm{s}$.

Um histograma para análise da intensidade sonora produzida pelas detonações também foi elaborado (Fig. 7). Ressalta-se que a maioria das observações está concentrada em regiões de valores inferiores a $115 \mathrm{~dB}$. No entanto, três valores encontramse substancialmente acima do limite estipulado pela NBR 9653 (ABNT, 2005), de $134 \mathrm{~dB}$, e apenas uma observação merece atenção, chegando a $147 \mathrm{~dB}$, alcançando níveis perniciosos às edificações proximais e/ou ao bem-estar da população, mas não o suficiente para provocar fissuras.

A reunião dos dados de velocidade máxima de partícula e a resultante $(V R)$ busca estabelecer uma relação das possíveis regiões mais e/ou menos afetadas pelas detonações. Obviamente que esta relação depende de alguns fatores como: a carga máxima por espera utilizada e a distância do ponto onde se concentra esta carga para o ponto monitorado. De forma geral, a região sul apresenta valores de velocidade de partícula próximos a 3 mm/s, enquanto na porção norte há proximidade destes 


\begin{tabular}{|c|c|c|c|c|c|c|c|}
\hline 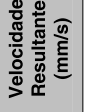 & $\begin{array}{ll}\stackrel{\circ}{\circ} \\
\stackrel{0}{0} \\
\stackrel{4}{=}\end{array}$ & 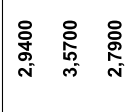 & 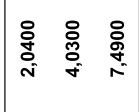 & 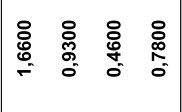 & 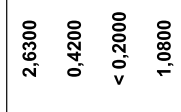 & 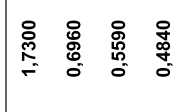 & 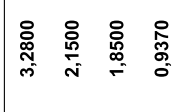 \\
\hline 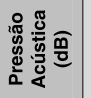 & $\begin{array}{ll}1 & 1\end{array}$ & $11 \stackrel{\mathscr{N}}{\approx}$ & $11 \stackrel{\infty}{=}$ & $\begin{array}{llll}1 & 1 & 1 & 1\end{array}$ & 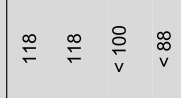 & $\stackrel{ }{\risingdotseq} \stackrel{ \pm}{=} \stackrel{ \pm}{=}$ & 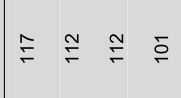 \\
\hline 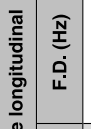 & 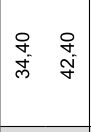 & 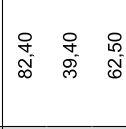 & 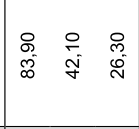 & 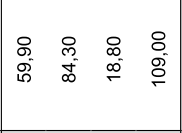 & 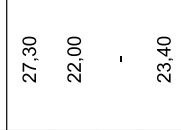 & 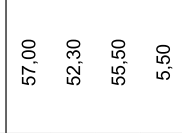 & 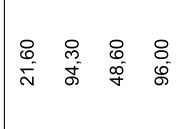 \\
\hline 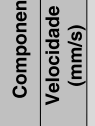 & $\mid \begin{array}{cc}\infty & 0 \\
0 & \infty \\
0 & 0 \\
0 & 0 \\
& 0\end{array}$ & 总 & 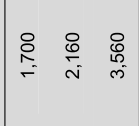 & $\begin{array}{cccc}0 & 0 & 0 & t \\
0 & 0 & 0 & 0 \\
0 & 0 & 0 & 0 \\
0 & 0 & 0\end{array}$ & 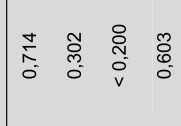 & 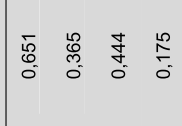 & 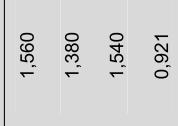 \\
\hline 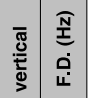 & 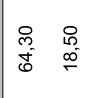 & 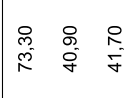 & 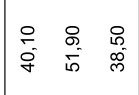 & 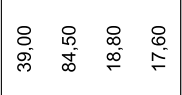 & 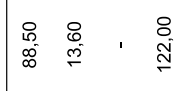 & 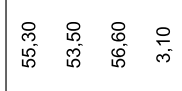 & 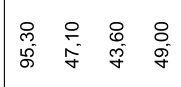 \\
\hline 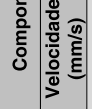 & $\underset{0}{0}$ & 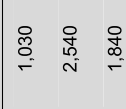 & 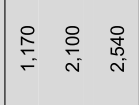 & 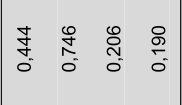 & $\begin{array}{cccc}0 & 0 & 0 & 0 \\
& 0 & 0 & 0 \\
= & 0 & 0 & 0 \\
0\end{array}$ & 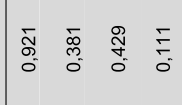 & 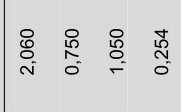 \\
\hline 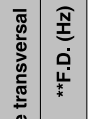 & 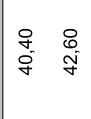 & 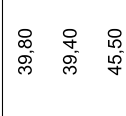 & 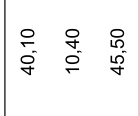 & 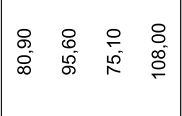 & 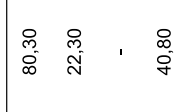 & 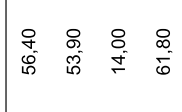 & 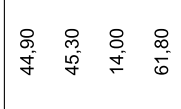 \\
\hline 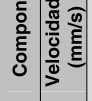 & \begin{tabular}{cc}
$\infty$ & 0 \\
\hdashline & $\infty$ \\
0 & $\infty$ \\
0 & $\infty$
\end{tabular} & 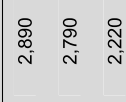 & 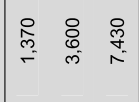 & 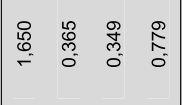 & 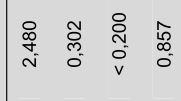 & 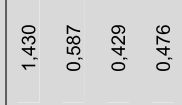 & 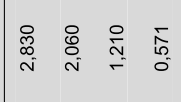 \\
\hline 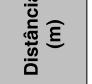 & 悉 & 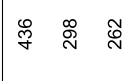 & 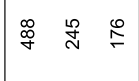 & 雚 & 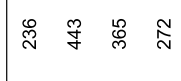 & 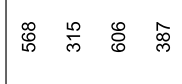 & 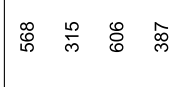 \\
\hline \% 要 & 赵 & $\underset{\substack{\text { N } \\
\text { N }}}{N}$ & 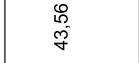 & 畩 & 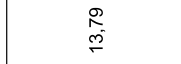 & 兽 & 电 \\
\hline 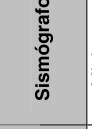 & & & & & & & \\
\hline 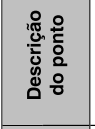 & \begin{tabular}{lll}
$\circ$ & $\circ$ \\
$\circ$ & $\circ$ \\
\hdashline
\end{tabular} & $\begin{array}{lll}\circ & \circ \\
\circ & \circ & \circ \\
\circ & \circ & \circ\end{array}$ & 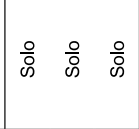 & 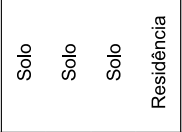 & 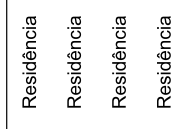 & 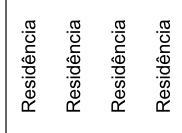 & 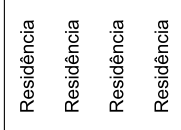 \\
\hline 䢒 & $\begin{array}{ll}- & 0 \\
0 & 0 \\
\vdots & 0 \\
0 & 5 \\
0\end{array}$ & 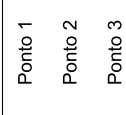 & 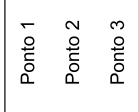 & 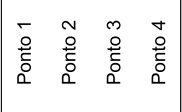 & 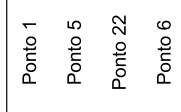 & 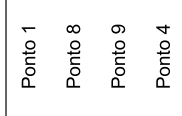 & 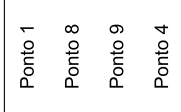 \\
\hline 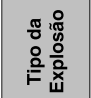 & $\begin{array}{c}\text { oprage } \\
\text { nẹp }\end{array}$ & $\begin{array}{c}\text { ouəage } \\
\text { nəop }\end{array}$ & 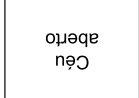 & 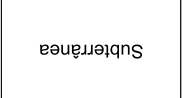 & $\begin{array}{l}\text { opəage } \\
\text { ṇฺว }\end{array}$ & $\begin{array}{c}\text { opyage } \\
\text { nę0 }\end{array}$ & $\begin{array}{c}\text { oupage } \\
\text { næ̣ว }\end{array}$ \\
\hline 产 & 产둔 & 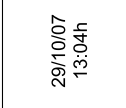 & 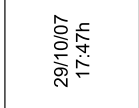 & 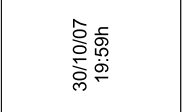 & 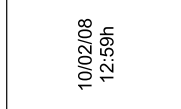 & 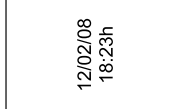 & 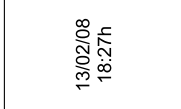 \\
\hline 号 & $\varangle$ & $\infty$ & 0 & ○ & ш & 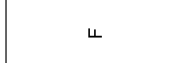 & 0 \\
\hline
\end{tabular}




\begin{tabular}{|c|c|c|c|c|c|c|c|}
\hline 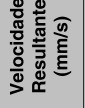 & 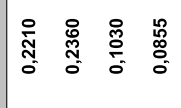 & 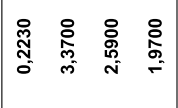 & 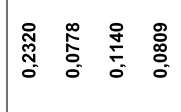 & 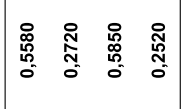 & $\frac{0}{0}$ & 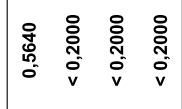 & 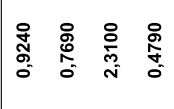 \\
\hline 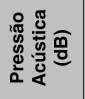 & $\stackrel{m}{=} \stackrel{\infty}{=} \stackrel{J}{=}$ & 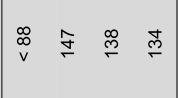 & $\stackrel{t}{=} \stackrel{8}{\circ} \stackrel{0}{\circ} \stackrel{8}{=}$ & $\stackrel{0}{=} \stackrel{6}{=} \stackrel{ \pm}{=}$ & $\stackrel{8}{\circ}$ & $\bar{i} \frac{8}{i} \frac{\circ}{v} \frac{8}{v}$ & 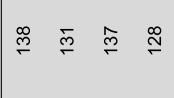 \\
\hline 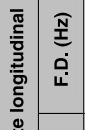 & 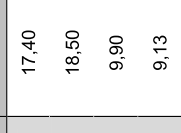 & 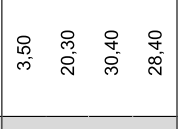 & 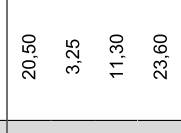 & 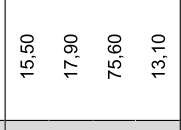 & $\frac{8}{\dot{\sigma}}$ & \begin{tabular}{|l}
8 \\
0 \\
6 \\
6 \\
6
\end{tabular} & 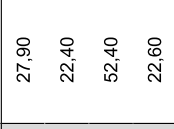 \\
\hline 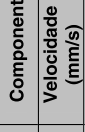 & 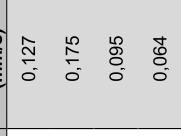 & 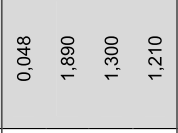 & 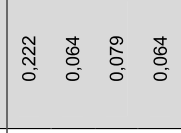 & 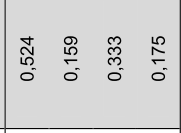 & $\frac{8}{\frac{8}{0}}$ & 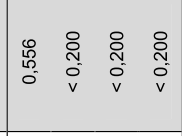 & 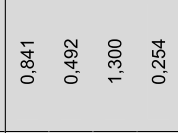 \\
\hline 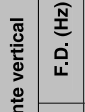 & 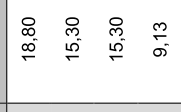 & 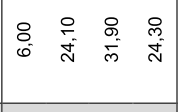 & 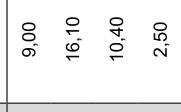 & 量总总 & $\frac{m}{\infty}$ & 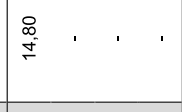 & 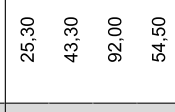 \\
\hline 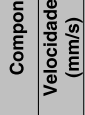 & 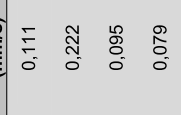 & 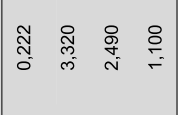 & 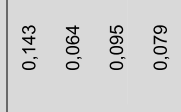 & 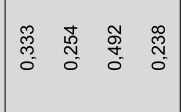 & 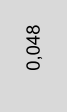 & 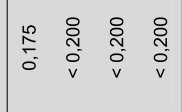 & 总 \\
\hline 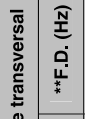 & 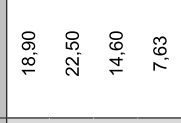 & 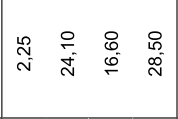 & 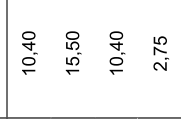 & 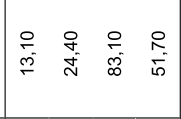 & $\stackrel{\circ}{N}$ & \begin{tabular}{|l|}
8 \\
0 \\
0 \\
0 \\
6
\end{tabular} & 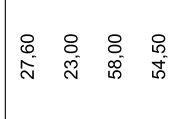 \\
\hline 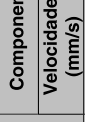 & 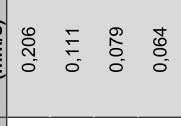 & 兽总 & 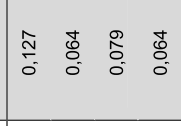 & 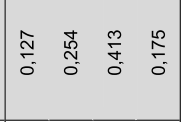 & $\begin{array}{l}\text { 京 } \\
0 \\
0\end{array}$ & $\begin{array}{llll}0 & 0 & 0 & 0 \\
i & 0 & 0 \\
0 & 0 & 0 \\
0 & 0 & 0 & 0 \\
& 0 & 0\end{array}$ & 壳 \\
\hline 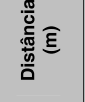 & 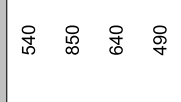 & 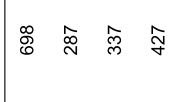 & 㗐 8 吉 $\stackrel{\infty}{\sim}$ & 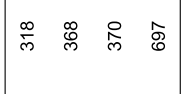 & $\stackrel{\mathscr{N}}{\infty}$ & 点 & 孛 \\
\hline 可 & 惫 & $\begin{array}{l}\mathscr{Q} \\
\stackrel{\leftrightarrow}{\infty} \\
\infty\end{array}$ & 总 & 产 & $\underset{\sim}{\alpha}$ & $\bar{\infty}_{\bar{\infty}}$ & $\stackrel{\infty}{\infty}$ \\
\hline 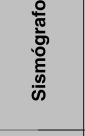 & & & & & 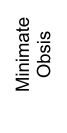 & & \\
\hline 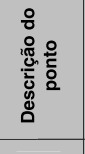 & 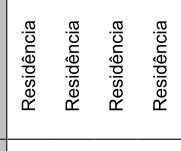 & 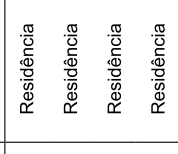 & 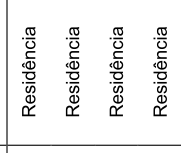 & 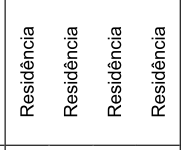 & 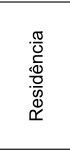 & 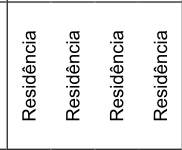 & 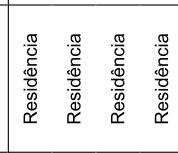 \\
\hline 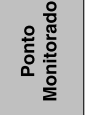 & 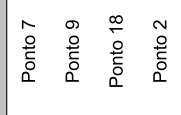 & 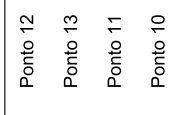 & 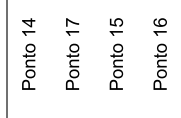 & 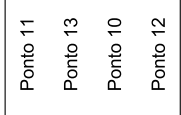 & $\begin{array}{l}0 \\
\text { D } \\
0 \\
0 \\
0 \\
0\end{array}$ & 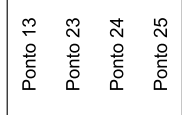 & 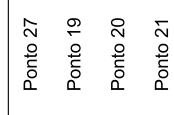 \\
\hline 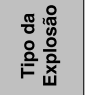 & 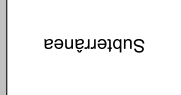 & $\begin{array}{c}\text { ouraqe } \\
\text { n९̣ }\end{array}$ & 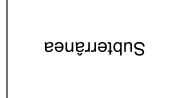 & 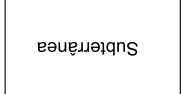 & $\begin{array}{l}\text { ouəage } \\
\text { nə⿻コ一 }\end{array}$ & $\begin{array}{c}\text { ourage } \\
\text { nẹj }\end{array}$ & 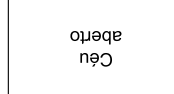 \\
\hline 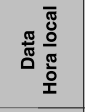 & 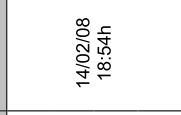 & 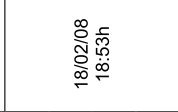 & 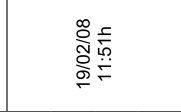 & 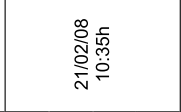 & 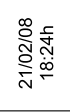 & 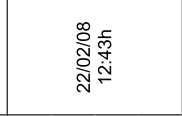 & 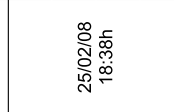 \\
\hline : & I & - & ᄀ & $x$ & \lrcorner & $\Sigma$ & z \\
\hline
\end{tabular}




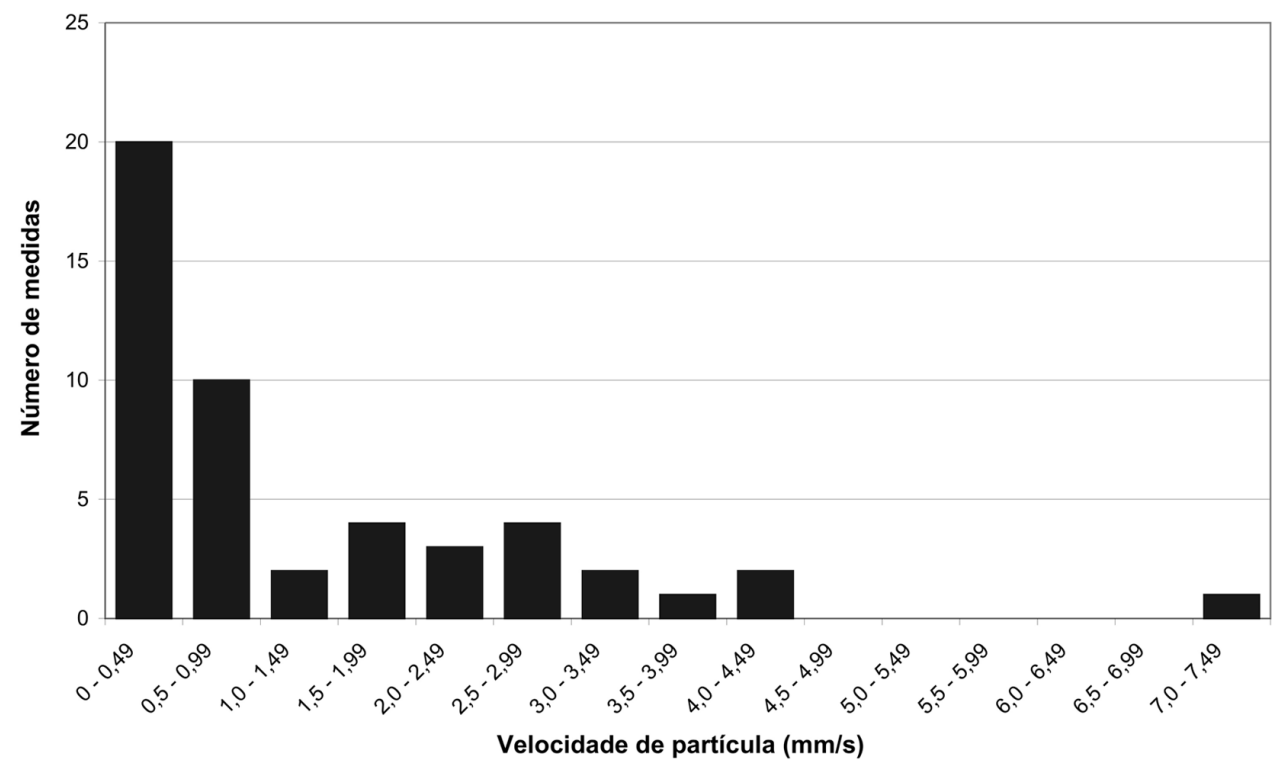

Figura 6 - Histograma dos 45 valores de velocidade da partícula resultante $(\mathrm{mm} / \mathrm{s})$ registrados nos 27 pontos de monitoramento. Nota-se que a maior parte dos valores concentra-se abaixo de $1 \mathrm{~mm} / \mathrm{s}$, o que se enquadra dentro dos limites estipulados pela ABNT.

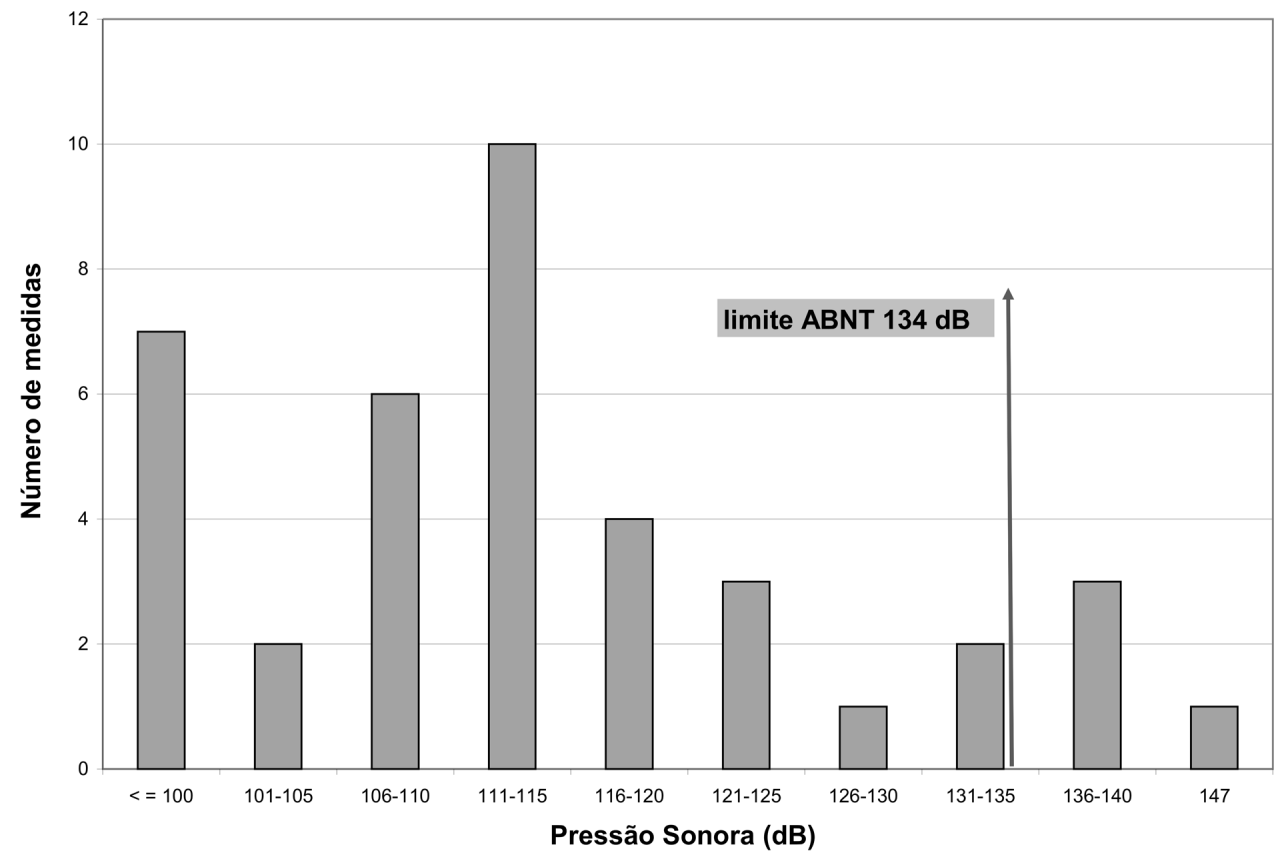

Figura 7 - Histograma dos valores de intensidade sonora obtidos para os pontos monitorados. Alguns valores superam o limite estipulado pela ABNT.

Tabela 3 - Intervalos de movimentação do chão para a intensidade Mercalli Modificada (MM).

\begin{tabular}{|c|c|c|c|c|c|c|c|c|c|}
\hline MM & I & II-III & IV & V & VI & VII & VIII & IX & X \\
\hline Aceleração Máxima $(\% g)$ & $<0,17$ & $0,17-1,4$ & $1,4-3,9$ & $3,9-9,2$ & $9,2-18$ & $18-34$ & $34-65$ & $65-124$ & $>124$ \\
\hline Velocidade Máxima $(\mathrm{mm} / \mathrm{s})$ & $<1$ & $1-11$ & $11-34$ & $34-81$ & $81-160$ & $160-310$ & $310-600$ & $600-1160$ & $>1160$ \\
\hline
\end{tabular}


valores com um ponto centrado em $7 \mathrm{~mm} / \mathrm{s}$, correspondente ao ponto 3 , demonstrando contraste de velocidade máxima de partícula na região.

Outra análise factível diz respeito à frequência de vibração das construções. Toda estrutura apresenta um intervalo de frequência de vibração natural, e todo corpo reage a uma vibração em virtude de sua inércia. Quando uma fonte externa vibra com frequência igual à frequência natural de certo sistema, este passa a vibrar com grande intensidade, e é dito estar em ressonância com a fonte. 0 fator desestabilizador de estruturas civis perante a propagação de ondas sísmicas, naturais ou artificiais, possui estreita relação com a frequência de ressonância. A NBR não faz nenhuma referência a este tipo de análise, e somente a título de comparação, a norma alemã DIN 4150 (Deutsche Norm, 1986) estabelece que, para habitações que possuem frequência entre 10 e $50 \mathrm{~Hz}$, o nível máximo de vibração admitido seria de $5-15 \mathrm{~mm} / \mathrm{s}$.

Estudos como 0 de Ahmad et al. (2005) fazem uma análise do período de oscilação para edifícios de diversos andares. De acordo com este estudo, uma residência baixa (sem andares superiores) possuiria um período natural de vibração típico de 0,1 segundo, ou seja, este tipo de estrutura possuiria uma frequência natural de aproximadamente $10 \mathrm{~Hz}, 0$ que se enquadra no intervalo citado pela norma alemã, e, também, no trabalho de Koppe et al. (2001). A maioria das frequências registradas nas três componentes apresenta valores muito superiores à frequência em questão (Tab. 2). Apesar de alguns valores de frequência estarem dentro desse intervalo (ver fogos C, E, F, G, H, J e K, da Tab. 2), os registros de frequência destas detonações mostram que seus valores de amplitude as exime de quaisquer efeitos prejudiciais às estruturas.

Uma última análise que pode ser feita diz respeito ao intervalo de movimentação do chão de acordo com a intensidade Mercalli Modificada (Tab. 3). 0 intervalo de velocidade de partícula resultante obtido pelos sismômetros de engenharia foi de 0,007 a 7,49 (mm/s), o qual se enquadra nos intervalos de I-III graus na escala Mercalli Modificada. Os respectivos efeitos descritos para este intervalo de intensidade são: "Sentido dentro de casa. Alguns objetos pendurados oscilam. Vibração parecida à da passagem de um caminhão leve. Duração estimada. Pode não ser reconhecido como um abalo sísmico". A partir desta análise pode-se ter uma noção dos efeitos ocorridos nas habitações dos moradores da cidade de Tucuruí, o que de fato coincide com as descrições dos moradores. Entretanto, esta análise trata-se de uma observação qualitativa, na qual não se tem controle da real relação da intensidade Mercalli Modificada com as fissuras existentes nestas habitações.

\section{Equação de atenuação}

Da energia liberada pelas detonações por explosivos, cerca de $90 \%$ é transferida ao ambiente circundante sob a forma de calor, de ruído e de vibrações. (Dinis da Gama, 1998). As vibrações ou ondas sísmicas atenuam-se fundamentalmente ao longo do seu percurso por dois mecanismos: 0 geométrico e 0 de dissipação (Schiappa de Azevedo \& Patrício, 2001). Na prática, as ondas não se atenuam sempre com a distância. Em meios estratificados e sua geometria o favorecer, as ondas podem concentrar-se ou sobrepor-se a outras refletidas, podendo medir-se maiores valores de vibração em pontos mais afastados.

Desta maneira, as propriedades geológicas, geotécnicas e consequentemente físicas de um maciço estão estritamente relacionadas às suas propriedades de atenuação de vibrações, de forma a produzir trens de ondas vibratórios característicos ao longo da trajetória de propagação. Assim, com a determinação dos fatores locais de atenuação em um programa de monitoramento de detonações, os níveis de pico de vibração de detonações futuras no local podem ser previstos com razoável precisão (Dallora Neto \& Ferreira, 2006).

Nessa determinação dos fatores locais de atenuação buscase estabelecer uma correlação entre as amplitudes das vibrações, quantificadas através da velocidade da vibração de partícula de pico [Eq. (1)], e os fatores relacionados à fonte de energia sobre os quais se tem controle, como a massa de explosivos detonada e a distância entre ela e o ponto monitorado.

A forma geral da equação que correlaciona essas três variáveis é do tipo:

$$
V=a(D E)^{b},
$$

sendo o parâmetro DE denominado distância escalonada e definido pela NBR 9653 (ABNT, 2005) como:

$$
D E=D / Q^{1 / 3} ;
$$

$D$ é a distância horizontal entre ponto de medição e a detonação (metros) e $Q$ é a carga máxima de explosivos a ser detonado por espera (kg).

É muito comum a detonação apresentar diversos valores de carga máxima por espera de acordo com a localização do furo. Neste caso, o valor considerado neste estudo é o maior dos valores de carga máxima por espera da detonação em questão. Como a Equação (2) é uma função de potência, não pode advir de um ajuste linear simples. Destarte, aplica-se a transformação logarítmica de forma a torná-la linear, obtendo-se então:

$$
\log (V)=\log (a)+b * \log (D E),
$$




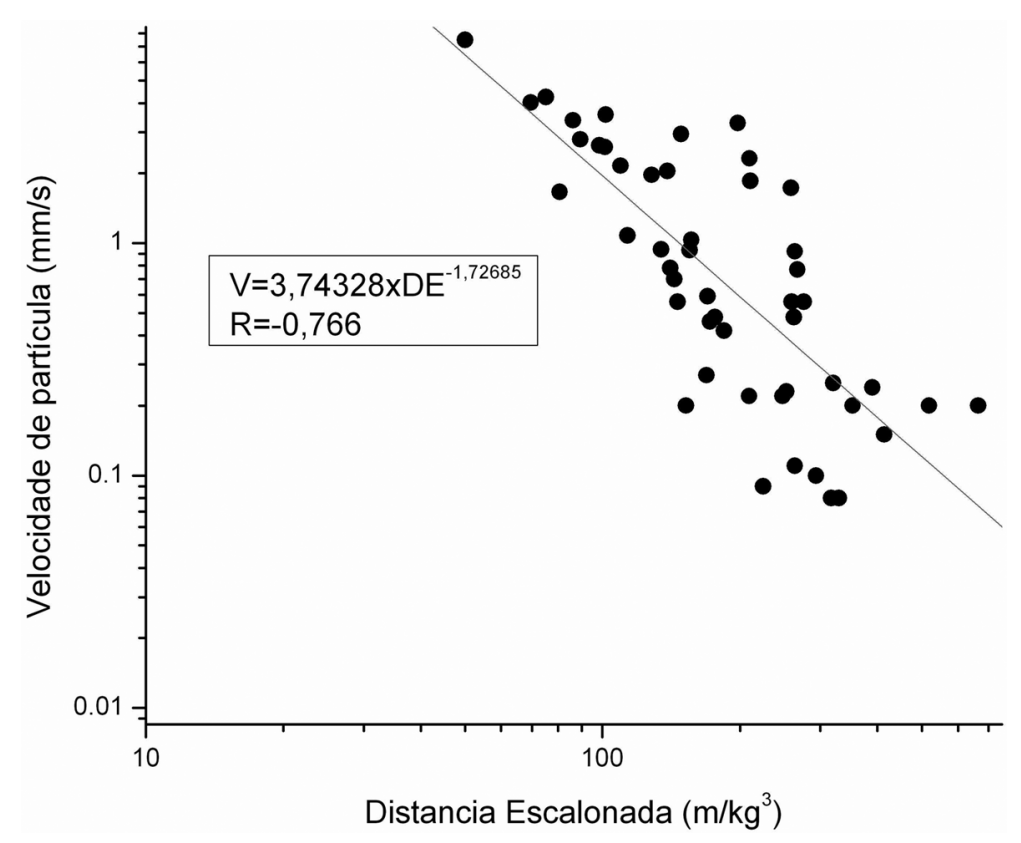

Figura 8 - Ajuste linear da reta referente à equação de atenuação das ondas obtida a partir dos registros sismográficos das detonações e da distância escalonada.

possibilitando a obtenção dos coeficientes linear (a), e angular (b) através de uma regressão linear simples.

De posse dos planos de fogo, de seus respectivos registros sismográficos e das distâncias, foi possível obter a equação de atenuação para a região, que apresenta a seguinte forma:

$$
\begin{aligned}
V= & 3,74328 \pm 0,48048 \times D E^{-1,72685 \pm 0,21143,} \\
& \text { com } R=0,76593 .
\end{aligned}
$$

A Figura 8 mostra 0 gráfico da equação de atenuação [Eq. (5)], obtido a partir dos registros sismográficos das detonações com um ajuste linear. Em uma análise geral, 0 gráfico mostra a relação praticamente direta entre a distância entre a explosão e o ponto monitorado maior e a dissipação de energia da frente de onda pelo meio de propagação. Desta maneira, as medidas mostram que 0 trajeto explosão-ponto de medição, percorrido pela onda, apresenta características geológicas e pedológicas suficientes para atenuação das ondas de forma a não comprometer as residências nas proximidades das obras ao menos para a carga máxima por espera utilizada nestas detonações. Considerando a menor distância de 176 metros implica que seria necessário, de acordo com a Equação (5), uma carga com valor aproximadamente 8 vezes maior do que 0 máximo utilizado. A dispersão dos valores em relação à reta pode estar relacionada à pequena diferença dos pontos de referência que foram extraídos dos planos de fogo e utilizados para o calculo das distâncias.

\section{CONCLUSÕES}

Os valores de velocidade da partícula resultante para os 42 registros sismográficos mostram-se bem inferiores ao valor máximo aceitável, segundo as recomendações da ABNT $(15 \mathrm{~mm} / \mathrm{s})$, para que não ocorra danos às residências próximas à obra de construção da Eclusa 2 da UHE de Tucuruí. Estes valores não apresentaram nenhuma correlação de acordo com 0 tipo de detonação realizada, a céu aberto ou subterrânea, e se enquadram em I-III graus da escala Mercalli Modificada.

A análise da intensidade sonora também mostra que a maioria dos valores está abaixo do limite estipulado pela ABNT. No entanto, a explosão ocorrida no dia 18.02.08, às 18h53min, alcançou níveis muito superiores aos estipulados pela NBR 9653. Desta maneira, não é descartada a possibilidade de explosões dessas dimensões causarem, não somente alerta à população, como pequenos danos estruturais às residências mais próximas. De fato, este pode ser o principal fator causador do alerta dos moradores, superando a expectativa dos efeitos causados pela velocidade de partícula. De acordo com a análise dos dados, recomenda-se que, ou carga máxima por espera seja reduzida, ou que seja modificada e/ou aperfeiçoada a proteção de atenuação das ondas sonoras, ou que os focos das explosões estejam a uma distância mínima de 450 metros das residências para que os danos por intensidade sonora sejam mitigados. 
A partir do exposto, é necessário que devido à baixa resistência das edificações próximas às detonações, seja realizado um estudo mais detalhado baseado nos materiais constituintes das residências, para conhecimento do máximo grau de vibração suportado pelas mesmas. A NBR 9653 não faz referência a este tipo de estudo e não leva em consideração a qualidade das residências.

\section{AGRADECIMENTOS}

Os autores agradecem a Eletronorte e Camargo Corrêa S.A. pelo apoio e execução do trabalho, ao técnico Mucélio (Eletronorte) pelo apoio ao campo, Kate Tomé de Souza pela confecção e produção dos mapas e das imagens. GSF agradece a Bolsa de produtividade do CNPq (302398/2007-4).

\section{REFERÊNCIAS}

ABNT. 1986. NBR 9653. Guia para avaliação dos efeitos provocados pelo uso de explosivos nas minerações em áreas urbanas (Procedimento). 2 ed. Associação Brasileira de Normas Técnicas, 8 p.

ABNT. 2005. NBR 9653. Guia para avaliação dos efeitos provocados pelo uso de explosivos nas minerações em áreas urbanas (Procedimento). 2 ed. Associação Brasileira de Normas Técnicas, 11 p.

AHMAD Z, AHMAD I, AKHTAR G \& ASIM S. 2005. Seismotectonics and Seismic Hazard Analysis in selected area of Margala Hills, Islamabad. Pakistan Journal of Hydrocarbon Research, 15: 65-72.

CAMARGO CORRÊA S.A. 2002a. Condições geológicas da área de implantação das obras. Eclusas de Tucuruí-Projeto Executivo. Relatório N. 46-MT-GEO-RT-E-01B-217.

CAMARGO CORRÊA S.A. 2002b. Relatório das investigações geo- lógico-geotécnicas. Eclusas de Tucuruí-Projeto Executivo. Relatório N. 46-MT-GEO-RT-E-003-010.

DALLORA NETO C \& FERREIRA GC. 2006. Controle de vibrações geradas por desmonte de rocha com explosivos. Estudo de caso: Calcário Cruzeiro, Limeira (SP). UNESP, Geociências, 25(4): 455-466.

DEUTSCHE NORM. 1986. DIN 4150. Erschütterungen im Bauwesen: Einwirkungen auf bauliche Anlagen. (Structural vibration: effects of vibration on structures).

DINIS DA GAMA. 1998. Ruídos e vibrações ligados à utilização dos explosivos e equipamentos. In: $1^{\circ}$ Seminário de Auditorias Ambientais Internas, Divisão de Minas e Pedreiras do Instituto Geológico e Mineiro, Portugal, $16 \mathrm{p}$.

INSTANTEL INC. 1998a. Operator manual - Blastmate III. Ontário, Canadá. $62 \mathrm{p}$.

INSTANTEL INC. 1998b. Operator manual - Minimate Plus. Ontário, Canadá. $37 \mathrm{p}$.

INSTANTEL INC. 2006. Software Blastware 8.12. Ontário, Canadá.

INSTANTEL INC. 2007. Software Blastware 8.12. Ontário, Canadá.

KOPPE JC, SALVADORETTI P, MUNARETTI E \& COSTA JFCL. 2001. Monitoramento geofísico de desmonte de rocha com utilização de explosivos em condições de risco elevado em zona urbana. Revista Escola de Minas, 54(4): 273-280.

REIL JP. 1998. Why people complain about blasting. Rock Products. p. $40-44$

SCHIAPPA DE AZEVEDO F \& PATRÍCIO J. 2001. Vibrações ambientes. Critérios de danos e de incomodidade. Actualidade e perspectivas futuras. Revista Técnica Acústica. 9 p.

\section{NOTAS SOBRE OS AUTORES}

George Sand França. Bacharel em Física pela Universidade Federal do Rio Grande do Norte, doutor em Geofísica, pela Universidade de São Paulo, atualmente é o professor do Observatório Sismológico, UnB. Área de pesquisa: sismicidade natural e induzida, estudo da estrutura da crosta e manto, divulgação em Geofísica e instrumentação para o ensino em Geociências. Lidera o grupo de pesquisa Sismicidade Induzida e Natural e é bolsista de produtividade do CNPq.

Marcos Alberto Rodrigues Vasconcelos. Geólogo formado pela Universidade de Brasília e mestre em Geofísica pela Universidade de São Paulo. Atualmente, doutorando da Universidade Estadual de Campinas com foco principal em petrografia, geologia estrutural e geofísica de estruturas de impacto de meteorito.

Cristiano Naibert Chimpliganond. Geólogo formado pela Universidade de Brasília e mestre em Geologia pela Universidade de Brasília. Atualmente, doutorando na mesma universidade com foco em sismicidade natural. Atua no Observatório Sismológico desde 1995 na análise de dados sísmicos. Área de interesse é sismicidade brasileira natural e induzida.

Sidinei Sebastião Tomás. Engenheiro Eletricista pela Universidade de Brasília, trabalha atualmente na instalação e manutenção de estações sismográficas e na instrumentação para o ensino em Geofísica. Área de pesquisa é tratamento de sinais e instrumentação. 